\title{
A methodologic framework to evaluate the number of cancers attributable to lifestyle and environment in Alberta
}

\author{
Anne Grundy PhD, Christine M. Friedenreich PhD, Abbey E. Poirier MSc, Farah Khandwala MSc, \\ Darren R. Brenner PhD
}

\section{Abstract}

Background: Previous research to estimate population attributable risks for cancer in Alberta has been limited. Attributable burden estimates are important for planning and implementing population-based cancer prevention strategies. This article describes a methodologic framework to estimate the number of incident cancers attributable to modifiable lifestyle and environmental risk factors in Alberta.

Methods: We estimated population attributable risks for cancer for exposures to 24 established cancer risk factors including tobacco consumption and environmental tobacco exposure, environmental factors, infectious agents, hormone therapies, dietary intake, obesity and physical inactivity. We used risk estimates to quantify the association between individual exposures and cancer sites as well as prevalence estimates for individual exposures in Alberta to estimate the proportion of cancer in Alberta that could be attributed to each exposure. These estimations were conducted in the context of a theoretical minimum risk principle, whereby exposures corresponding to the lowest levels of population risk were used as the comparisons for alternative exposure levels.

Inte rpretation: We outline the main methodologic principles for the protocol used in evaluating population attributable risks for modifiable lifestyle and environmental risk factors for cancer in Alberta. The data produced by this project will provide important information concerning which known cancer risk factors are responsible for the largest proportions of cancer in Alberta and could inform future cancer prevention strategies.

$\mathrm{P}$ opulation attributable risks provide an estimate of the proportion of a given disease that can be attributed to exposure to an individual risk factor. ${ }^{1}$ These estimates inform public health planning and disease prevention programs by identifying exposures that have the greatest impact on disease incidence.

Limited research effort has focused on estimating these population attributable risks for modifiable risk factors and cancer in Canada and more specifically in Alberta. A 2009 analysis of the economic burden of occupational cancers in Alberta $^{2}$ did not include any population-based estimates of attributable fractions of cancer for nonoccupational exposure. In addition, although there have been a number of efforts in recent years to address the population attributable risks of individual risk factors for Canada or other provinces individually, ${ }^{3-9}$ no systematic estimations of attributable cancer incidence across the spectrum of modifiable lifestyle and environmental risk factors have been completed in Canada. Because information concerning the fraction of cancer attributable to individual risk factors is essential for both resource allocation and implementation of population-based cancer prevention strategies, additional research that identifies priorities for modifiable cancer risk factors in Alberta is needed. To address this need, we conducted a systematic estimation of the burden of cancer attributable to all accepted modifiable risk factors in Alberta. In this paper we describe the methodologic framework that was used to identify relevant exposure-cancer

Competing interests: None declared.

This article has been peer reviewed.

Correspondence to: Darren Brenner, Darren.Brenner@ albertahealthservices.ca

CMAJ Open 2016. DOI:10.9778/cmajo.20150068 
associations and to systematically estimate the proportion of incident cancer cases attributable to previous exposure to modifiable risk factors among Albertans. As the first in a series of articles that will be presented concerning population attributable cancer risks in Alberta, this article provides an overview of the general methodologic principles used for all exposures. Further articles will provide greater details regarding exposure-specific methods.

\section{Methods}

We selected modifiable lifestyle and environmental risk factors for cancer for inclusion in this project on the basis of a literature search of 3 main sources: the International Agency for Research on Cancer Monograph series, the World Cancer Research Fund report, ${ }^{10}$ and recent meta-analyses, large prospective cohort studies and the current epidemiologic literature. Selected exposures can be classified into the categories of tobacco consumption and exposure, environmental factors (air, water and soil contaminants and components), infectious agents, hormone therapies, dietary intake characteristics and energy imbalance. The full list of exposures and cancer sites of interest for this project is shown in Table 1. A secondary consideration in the selection of exposures was the expected range of population prevalence of the individual exposures, given that those with very low prevalence are not of high value in population-based preventive efforts assuming moderate risk associations.

\section{Data sources}

Three main types of data are required for the estimation of population attributable risks: the magnitude of the risk association between individual exposures and cancer sites, estimates of the population prevalence of individual exposures, and current age- and sex-specific cancer incidence data for the associated cancer sites. We obtained these data and used them in the analyses for each exposure/cancer site pair of interest.

\section{Risk estimate data}

As the objective of this work was to produce population attributable cancer risk estimates representative of the general Alberta population, we sought risk estimates applicable to this population from several sources of epidemiologic data. We reviewed reports from international collaborative groups/ panels (e.g., International Agency for Research on Cancer, World Cancer Research Fund) and the current published peer-reviewed literature in PubMed to extract estimates of risk for each exposure and cancer site of interest for this project. Following this review, we selected estimates of relative risk (RR), hazard ratio, odds ratio or incidence rate ratio according to the hierarchy shown in Figure 1. This strategy assumed that the individual risk estimates reflect biological phenomena, such that results from populations outside Alberta or Canada are applicable to the Alberta population. For individual exposures, we used risk estimates corresponding to the highest available rank on the hierarchy in exposurespecific analyses. For example, if risk estimates were available from both international collaborative panels and recent metaanalyses, we used the estimate from an international collaborative panel because it corresponded to a higher rank on the hierarchy presented in Figure 1. This process produced a single risk estimate for each exposure/cancer site pair, stratified by sex where appropriate, that was used in the estimation of population attributable risks.

\section{Exposure prevalence data}

Prevalence data for the exposures of interest were collected at the provincial level. We obtained prevalence data from a search of results from Statistics Canada surveys, publicly available government databases, published peer-reviewed literature and consultation with relevant experts. We selected data sources for estimation of exposure prevalence according to the hierarchy shown in Figure 2, where data from the highestranking available source were used. Where available, age- and sex-specific measures of exposure prevalence were obtained.

For all potential sources of exposure prevalence data, we considered several characteristics of available data sources. First, we used a theoretical minimum risk principle to characterize relevant measures of exposure. ${ }^{12}$ This principle refers to the concept that for meaningful population attributable risk estimates, alternative population levels of exposure or exposure distributions must be compared. Under this model, the

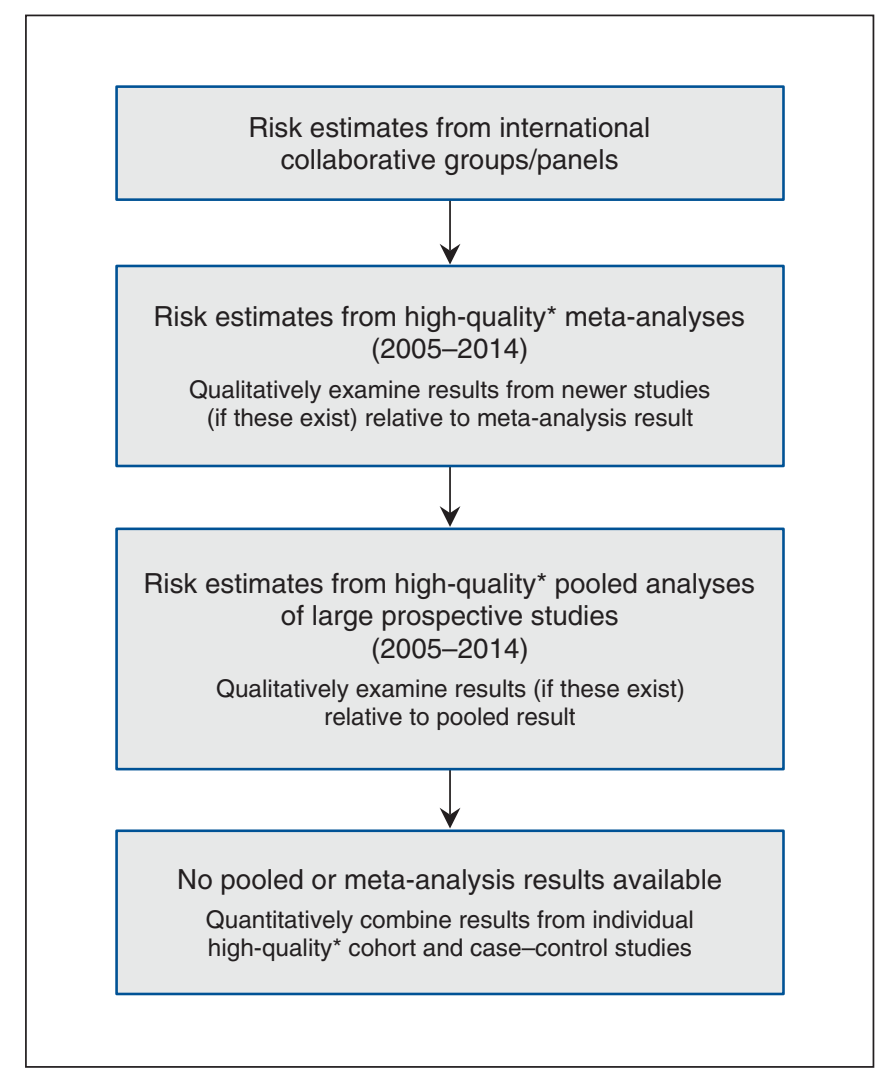

Figure 1: Hierarchy for selection of risk estimates used in this project. ${ }^{*}$ Quality determined with the use of the STrengthening the Reporting of OBservational studies in Epidemiology (STROBE) guidelines for cohort and case-control studies and Meta-analysis Of Observational Studies in Epidemiology (MOOSE) guidelines for meta-analysis. 
Table 1: Exposure and cancer site associations of interest to be included in this project

\begin{tabular}{|c|c|c|}
\hline Paper no. & Exposure & $\begin{array}{c}\text { Cancer types consistently associated } \\
\text { with exposure }\end{array}$ \\
\hline \multirow[t]{17}{*}{1} & Active tobacco & Lung \\
\hline & & Oral cavity and pharynx \\
\hline & & Esophagus \\
\hline & & Stomach \\
\hline & & Liver \\
\hline & & Pancreas \\
\hline & & Colorectum \\
\hline & & Larynx \\
\hline & & Cervix \\
\hline & & Ovary (mucinous) \\
\hline & & Urinary bladder \\
\hline & & Kidney \\
\hline & & Acute myeloid leukemia \\
\hline & Passive tobacco & Lung \\
\hline & & Oral cavity and pharynx \\
\hline & & Esophagus \\
\hline & & Larynx \\
\hline \multirow[t]{6}{*}{2} & High alcohol intake & Mouth \\
\hline & & Pharynx \\
\hline & & Larynx \\
\hline & & Liver \\
\hline & & Colorectum \\
\hline & & Breast (pre- and postmenopausal) \\
\hline \multirow[t]{7}{*}{3} & Overweight/obesity (body mass index $>25 \mathrm{~kg} / \mathrm{m}^{2}$ ) & Breast (postmenopausal) \\
\hline & & Colorectum \\
\hline & & Esophagus (adenocarcinoma) \\
\hline & & Kidney \\
\hline & & Endometrium \\
\hline & & Gall bladder \\
\hline & & Pancreas \\
\hline \multirow[t]{6}{*}{4} & Physical inactivity & Breast (postmenopausal) \\
\hline & & Colorectum \\
\hline & & Endometrium \\
\hline & & Lung \\
\hline & & Ovary \\
\hline & & Prostate \\
\hline \multirow[t]{9}{*}{5} & Low vegetable intake (nonstarchy) & Oral cavity and pharynx \\
\hline & & Esophagus \\
\hline & & Stomach \\
\hline & & Larynx \\
\hline & Low fruit intake & Oral cavity and pharynx \\
\hline & & Esophagus \\
\hline & & Stomach \\
\hline & & Larynx \\
\hline & & Lung \\
\hline \multirow[t]{2}{*}{6} & High red meat intake & Colorectum \\
\hline & High processed meat intake & Colorectum \\
\hline 7 & Low fibre intake & Colorectum \\
\hline \multirow[t]{4}{*}{8} & Low vitamin D & Colorectum \\
\hline & & Breast \\
\hline & High salt intake & Stomach \\
\hline & Low dietary calcium intake & Colorectum \\
\hline \multirow[t]{7}{*}{9} & Hormone therapies & \\
\hline & Oral contraceptive use & Breast \\
\hline & & Endometrium \\
\hline & & Ovary \\
\hline & Hormone replacement therapy & Breast \\
\hline & & Endometrium \\
\hline & & Ovary \\
\hline \multirow[t]{14}{*}{10} & Infectious agents & \\
\hline & Human papillomavirus & Cervix \\
\hline & & Vagina \\
\hline & & Penis \\
\hline & & Anus \\
\hline & & Vulva \\
\hline & & Oropharynx \\
\hline & Helicobacter pylori & Stomach \\
\hline & Epstein-Barr virus & Non-Hodgkin's lymphoma \\
\hline & & Hodgkin's lymphoma \\
\hline & & Burkitt's lymphoma \\
\hline & & Nasopharyngeal carcinoma \\
\hline & Hepatitis B virus & Liver \\
\hline & Hepatitis C virus & Liver \\
\hline 11 & Ultraviolet radiation & Melanoma \\
\hline 12 & Radon & Lung \\
\hline 13 & Air pollution (fine particulate matter $\left[\mathrm{PM}_{2.5}\right]$ ) & Lung \\
\hline
\end{tabular}


exposure distribution that corresponds to the lowest level of population risk is used as the comparison. ${ }^{12}$ To apply this concept to our analysis, for risk factors where complete lack of exposure is possible, individuals with any exposure to the risk factor were considered exposed, and the prevalence of all potential levels of exposure (if more than 1 level was appropriate) was obtained for use in calculations of population attributable risk. For example, with active tobacco exposure, both current and former smokers were considered to have some level of exposure, and those who had never smoked served as the comparison (i.e., minimum-risk) group. For risk factors where all individuals have some level of exposure, such that zero is not a relevant value (e.g., body mass index), we used the level of exposure associated with the lowest degree of cancer risk as the "unexposed" group and used the prevalence of higher levels of exposure (e.g., overweight and obese for body mass index) in population attributable risk calculations.

Because the effect of exposure on cancer risk is assumed to be the product of a previous exposure, we identified a biologically meaningful latency period for all exposures from the literature. To quantify this latency period, we distinguished between the theoretical latency period (the time between initiation of exposure and cancer diagnosis) and the measured

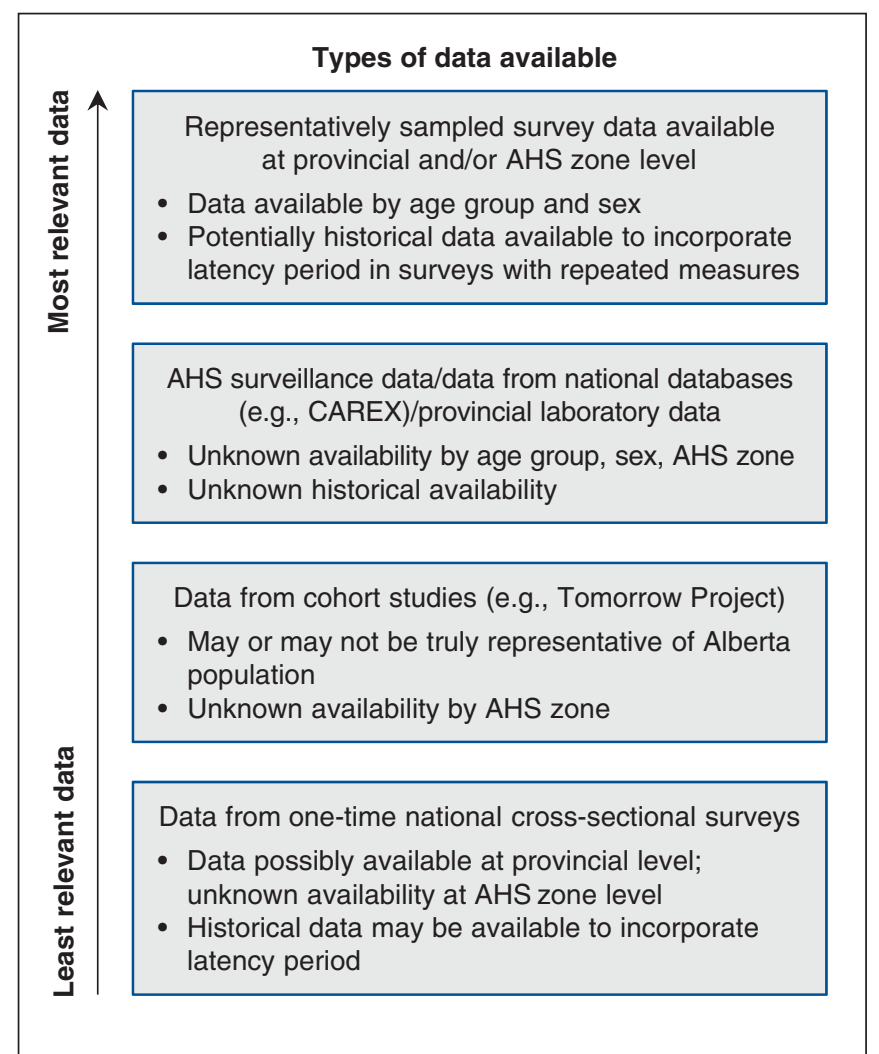

Figure 2: Hierarchy for selection of exposure prevalence estimates. AHS = Alberta Health Services, CAREX = CARcinogen EXposure, a multi-institution research project dedicated to generating evidencebased carcinogen surveillance in Canada (www.carexcanada.ca). The Tomorrow Project is a large prospective cohort study being conducted in Alberta to study health outcomes including cancer. ${ }^{11}$ The project, which began in 2000 , is recruiting adults aged 35-69 who will be followed for up to 50 years. latency period (the time between exposure measurement and cancer diagnosis) (Figure 3). For these analyses and the selection of appropriate exposure prevalence data, we attempted to quantify the measured latency period and subsequently refer to this as the "latency period" for simplicity. To quantify the measured latency period we used the average time between exposure measurement and cancer diagnosis, obtained from high-quality cohort studies. We evaluated the quality of cohort studies on the basis of the size of the cohort, methods of exposure assessment and length of follow-up, where large cohorts with detailed exposure and longer follow-up were considered to be of highest quality. We then compared this information concerning the latency period with the time for which high-quality data on exposure prevalence were available. Where possible, we selected for analysis prevalence estimates corresponding to the midpoint of the range of potential latency periods identified from cohort studies. For example, if cohort studies identified potential latency periods as between 9 and 13 years, exposure prevalence data incorporating an 11-year latency period were selected for analysis if available. When high-quality data on exposure prevalence within the range of latency periods for a given exposure could not be identified, we used the closest available estimates.

We also evaluated the availability of exposure data in units or measures reflective of the selected risk estimates such that, where possible, an exposure data source with units similar to those of the selected risk estimate was identified. In instances in which we used a less-representative source of exposure data (e.g., cohort instead of survey data), we performed sensitivity analyses where possible to characterize the potential impact of this choice on estimates of population attributable risk.

\section{Cancer incidence data}

Data on current cancer incidence levels in Alberta were needed to quantify the number of current incident cancer cases that could be attributed to individual exposures. We obtained data on cancer incidence for 2012 (the most recent year for which complete data were available) from the Alberta Cancer Registry. Cases were classified with the use of the International Classification of Diseases for Oncology, 3rd Edition (ICD-O-3) and the International Agency for Research on Cancer rules for determining multiple primary sites. The complete list of cancer sites and ICD-O-3 codes used for this request is found in Appendix 1, available at www. cmajopen.ca/content/4/3/E471/suppl/DC1.

\section{Statistical analysis}

We used the formula of Levin, ${ }^{13}$ shown in equation 1 , as the basis to estimate most population attributable risk values. This method uses information on the prevalence of a given exposure in the Alberta population in combination with a RR measure to estimate population attributable risk.

$$
\text { Equation 1: } P A R=(P e(R R-1)) /(1+[P e(R R-1)])
$$

where $P A R=$ population attributable risk and $P e=$ prevalence of exposure. 
For risk factors with multiple levels of exposure (i.e., low, medium, high), we used a variant of this formula, similar to that used by Parkin ${ }^{14}$ (equation 2). In this formula, estimates of prevalence in each exposure category $\left(P e_{x}\right)$ and excess relative risk (ERR), where ERR $=\mathrm{RR}-1$, are substituted into the Levin formula.

Equation 2: $P A R=\left(\left(P e_{1} \times E R R_{1}\right)+\left(P e_{2} \times E R R_{2}\right)+\ldots+\left(P e_{x}\right.\right.$ $\left.\left.\times E R R_{x}\right)\right) /\left(1+\left(\left(P e_{1} \times E R R_{1}\right)+\left(P e_{2} \times E R R_{2}\right)+\ldots+\left(P e_{x} \times\right.\right.\right.$ $\left.\left.E R R_{x}\right)\right)$ )

We used equation 1 to estimate population attributable risk for exposure to ultraviolet radiation, disinfection byproducts, and oral contraceptives and hormone replacement therapy, and equation 2 to estimate population attributable risk for exposure to tobacco (both active and passive), intake of fruits/vegetables, red/processed meat, alcohol and fibre, overweight/obesity and physical inactivity.

We evaluated population attributable risks associated with infectious disease exposures using 1 of 2 formulae, similar to the methods of de Martel and colleagues. ${ }^{15}$ Population attributable risk is estimated retrospectively in equation 3 , with the prevalence of exposure among cases being used as a substitute for prevalence of exposure in the population. ${ }^{16}$

Equation 3: $P A R=P c((R R-1)) / R R$

where $P c=$ prevalence of exposure among cases. We used equation 3 for Helicobacter pylori, Epstein-Barr virus, hepatitis
$B$ virus and hepatitis $C$ virus. As the value of the $R R$ increases, the quantity $(\mathrm{RR}-1) / \mathrm{RR}$ approaches a limit of 1 , and the population attributable risk can be approximated with the use of equation 4.

\section{Equation 4: $P A R=P c$}

We used equation 3 for human papillomavirus and all cancer sites except the cervix, as mechanistic information suggests the presence of infection is likely to cause cancer for these infections. In situations where infection is considered a necessary cause of cancer (i.e., human papillomavirus and cervical cancer), $100 \%$ of cases were considered to be attributed to infection, and therefore no population attributable risk estimations were done (equation 4).

We used exposure-specific methods that will be described in more detail in further articles for air pollution, radon and consumption of salt, dietary calcium and vitamin $\mathrm{D}$.

A summary of the method used for each exposure included in the full population attributable risk project is shown in Table 2.

To estimate $95 \%$ confidence intervals around population attributable risk estimates, we used Monte Carlo simulation methods wherein the RR estimates were drawn from a log normal distribution, prevalence estimates were drawn from a binomial distribution, and incidence estimates were drawn from a Poisson distribution. Parameters for the distributions were defined by reported point estimates and confidence intervals. We drew 10000 samples and used the 2.5th and

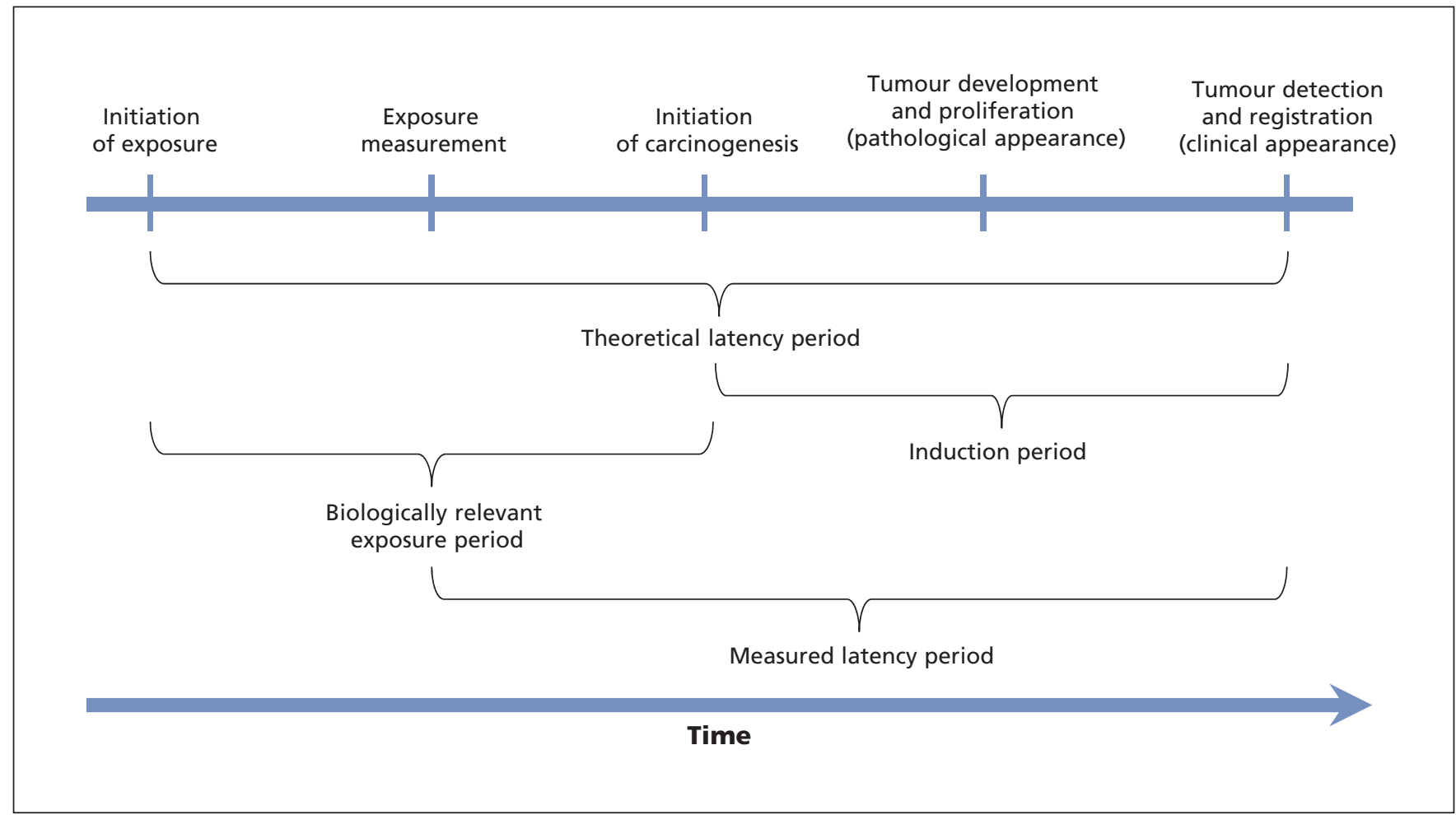

Figure 3: Proposed model of carcinogenesis related to the adverse exposure of interest. The measured latency period is referred to as the latency period for the purposes of estimating population attributable cancer risks in Alberta. 


\begin{tabular}{|c|c|}
\hline Equation & Exposure \\
\hline Equation 1: PAR $=(P e(R R-1)) /(1+[P e(R R-1)])$ & $\begin{array}{l}\text { Tobacco (passive) } \\
\text { Ultraviolet radiation } \\
\text { Disinfection by-products } \\
\text { Low vitamin } D \\
\text { High salt intake } \\
\text { Low dietary calcium intake }\end{array}$ \\
\hline Equation 2: $P A R=P C((R R-1)) / R R$ & $\begin{array}{l}\text { Helicobacter pylori } \\
\text { Epstein-Barr virus } \\
\text { Hepatitis B virus } \\
\text { Hepatitis C virus }\end{array}$ \\
\hline Equation 3: $P A R=P C$ & $\begin{array}{l}\text { Human papillomavirus for all cancer } \\
\text { sites except cervix }\end{array}$ \\
\hline $\begin{array}{l}\text { Equation 4: } P A R=\left(\left(P e_{1} \times E R R_{1}\right)+\left(P e_{2} \times E R R_{2}\right)+\ldots\right. \\
\left.+\left(P e_{x} \times E R R_{x}\right)\right) /\left(1+\left(\left(P e_{1} \times E R R_{1}\right)+\left(P e_{2} \times E R R_{2}\right)+\ldots\right.\right. \\
\left.\left.+\left(P e_{x} \times E R R_{x}\right)\right)\right)\end{array}$ & $\begin{array}{l}\text { Tobacco (active) } \\
\text { Oral contraceptives } \\
\text { Hormone replacement therapy } \\
\text { Overweight/obesity } \\
\text { Low fruit and vegetable intake } \\
\text { Red/processed meat intake } \\
\text { High alcohol intake } \\
\text { Low dietary fibre intake } \\
\text { Physical activity/inactivity }\end{array}$ \\
\hline Individualized methods & $\begin{array}{l}\text { Air pollution } \\
\text { Radon } \\
\text { Insufficient fruit and vegetable } \\
\text { intake } \\
\text { Red/processed meat intake } \\
\text { Insufficient fibre intake } \\
\text { Alcohol consumption }\end{array}$ \\
\hline
\end{tabular}

97.5th percentiles of the resulting population attributable risk distribution as the lower and upper limits of a $95 \%$ confidence interval. ${ }^{17,18}$ Wherever possible and when appropriate, we performed these estimations for individual sex and age groups.

These different methods for estimating population attributable risks resulted in a set of proportions of cases by cancer site that can be attributed to these selected exposures. To estimate the specific number of cases of cancer in Alberta that could be attributed to individual exposures, we applied these proportions to the 2012 cancer incidence data from the Alberta Cancer Registry. Where possible, we also performed these estimations for age- and sex-specific groups.

\section{Interpretation}

The estimation of population attributable risks for cancer for modifiable lifestyle and environmental risk factors for Alberta will allow the proportion of cancer diagnosed in the province that is theoretically preventable to be quantified. This knowledge has implications for cancer prevention as it will identify the modifiable characteristics for which changes in the provincial risk profile are likely to have the greatest impact on Alberta's cancer burden.

The project most comparable to ours was conducted by Parkin and colleagues ${ }^{14,19-33}$ to estimate population attributable risks for cancer risk factors in the United Kingdom in
2010. We adopted the general approach used by Parkin and colleagues $^{14}$ for our project and adapted it for several of the exposure-specific methods to apply to the population of Alberta. These similarities will allow our results and those of Parkin and colleagues to be directly comparable. Our analysis has also been informed by previous studies of population attributable cancer risk for the individual exposures included in our project, particularly studies conducted in Canada. In 2014, Brenner ${ }^{4}$ estimated that $3.5 \%$ and $7.9 \%$ of cancers in Canada could be attributed to overweight/obesity and physical inactivity respectively. The methods we have chosen to assess the impact of these exposures in Alberta will be identical, and thus our estimates will be directly comparable to those of Brenner. Cancer Care Ontario also published population attributable risk estimates of the cancer burden attributable to tobacco, ${ }^{5}$ alcohol $^{34}$ and obesity ${ }^{35}$ in Ontario; similar methods to those that we propose were used. In addition, several investigators have attempted to quantify the proportion of lung cancer attributable to residential radon exposure for Canada as a whole $e^{7,8,36}$ as well as for Ontario specifically. ${ }^{6}$ Our estimation of the effect of residential radon on lung cancer incidence in Alberta uses the method developed by Brand and colleagues, ${ }^{7}$ and we will employ the same data source used in previous analyses for Canada ${ }^{8}$ and Ontario. ${ }^{6}$ The implementation of methods that have previously been used to evaluate population attributable cancer risks in general ${ }^{13}$ 
and for individual exposures ${ }^{4-8,34-36}$ makes our estimates directly comparable to these previous efforts.

\section{Limitations}

There are some limitations to our approach. First, to prevent duplication of work being completed by the Occupational Cancer Research Centre at Cancer Care Ontario concerning the burden of occupational cancer in Canada, ${ }^{37}$ our protocol does not consider the influence of exposures that occur in an occupational setting. Furthermore, the accuracy of the estimates of population attributable risk that will be produced will necessarily be limited by the extent to which the prevalence estimates for individual exposures are representative of the true exposure levels in Alberta. For example, for several dietary exposures, we estimated exposure prevalence using data from Alberta's Tomorrow Project, a population-based cohort study. ${ }^{11}$ Participants in the project are volunteers, and the potential for volunteer bias (systematic differences between those who volunteer for the study and those who do not) will need to be considered when evaluating whether the prevalence of individual exposures in the cohort is representative of exposure levels in the general Alberta population.

Our analyses are further limited by the fact that we were unable to account for potential interactions between risk factors when quantifying population attributable risks. As many cancers have multiple causes, it is reasonable to suspect some cancer cases may have been caused by interactions between risk factors investigated in our project. In our analysis, each risk factor was considered individually, such that cancers that may have been the result of a combination of risk factors would have been counted twice. To accurately account for these potential interactions in our population attributable risk estimates, exposure data with estimations of the joint distribution of risk factors that may interact are required, but these were not consistently available for Alberta across the range of exposures included in our project. We also estimated that the period between exposure and cancer incidence (referred to in the analyses as latency period) would be the midpoint of observed follow-up times between exposure assessment and cancer incidence in large cohort studies. We did not conduct subsequent sensitivity analyses to examine the impact of this choice by modelling the extent to which changes in exposure prevalence across a range of different latency periods would have influenced estimates of population attributable risk.

Through a national collaborative partnership project funded by the Canadian Cancer Society (grant 703106), we will be conducting a similar series of estimations at the national level in Canada. We will be working to address the methodologic limitations listed above with a series of statistical advancements that will include consideration of joint risk factors and projection of future avoidable disease burden.

\section{Conclusion}

The results from the analyses described in this article will estimate population attributable cancer risks for modifiable lifestyle and environmental risk factors for cancer in Alberta. Each of the exposure-specific papers outlined in Table 1 will follow in this journal. The data produced by this project will provide important information concerning which known cancer risk factors are responsible for the largest proportions of cancer in Alberta and could inform future cancer prevention strategies.

\section{References}

1. Walter SD. Local estimates of population attributable risk. 7 Clin Epidemiol 2010;63:85-93.

2. Orenstein M, Chen J, Dall T, et al. The economic burden of occupational cancers in Alberta. Calgary: Alberta Health Services; 2009.

3. Neutel CI, Morrison H. Could recent decreases in breast cancer incidence really be due to lower HRT use? Trends in attributable risk for modifiable breast cancer risk factors in Canadian women. Can 7 Public Health 2010;101: 405-9.

4. Brenner DR. Cancer incidence due to excess body weight and leisure-time physical inactivity in Canada: implications for prevention. Prev Med 2014;66: 131-9.

5. Cancer risk factors in Ontario: tobacco. Toronto: Cancer Care Ontario; 2014.

6. Peterson E, Aker A, Kim J, et al. Lung cancer risk from radon in Ontario, Canada: How many lung cancers can we prevent? Cancer Causes Control 2013; 24:2013-20

7. Brand KP, Zielinski JM, Krewski D. Residential radon in Canada: an uncertainty analysis of population and individual lung cancer risk. Risk Anal 2005; 25:253-69.

8. Chen J, Moir D, Whyte J. Canadian population risk of radon induced lung cancer: a re-assessment based on the recent cross-Canada radon survey. Radiat Prot Dosimetry 2012;152:9-13.

9. Cancer risk factors in Ontario: evidence summary. Toronto: Cancer Care Ontario; 2013.

10. Food, nutrition, physical activity, and the prevention of cancer: a global perspective. Washington (DC): World Cancer Research Fund/American Institute for Cancer Research; 2007.

11. Bryant H, Robson PJ, Ullman R, et al. Population-based cohort development in Alberta, Canada: a feasibility study. Chronic Dis Can 2006;27:51-9.

12. Murray CJ, Ezzati M, Lopez AD, et al. Comparative quantification of health risks conceptual framework and methodological issues. Popul Health Metr 2003. $1: 1$

13. Levin ML. The occurrence of lung cancer in man. Acta Unio Int Contra Cancrum 1953;9:531-41.

14. Parkin DM. 1. The fraction of cancer attributable to lifestyle and environmental factors in the UK in 2010. Br 7 Cancer 2011;105(Suppl 2):S2-5.

15. de Martel C, Ferlay J, Franceschi S, et al. Global burden of cancers attributable to infections in 2008: a review and synthetic analysis. Lancet Oncol 2012;13: $607-15$

16. Miettinen OS. Proportion of disease caused or prevented by a given exposure, trait or intervention. Am 7 Epidemiol 1974;99:325-32.

17. Renehan AG, Soerjomataram I, Tyson M, et al. Incident cancer burden attributable to excess body mass index in 30 European countries. Int 7 Cancer 2010; 126:692-702.

18. Lee IM, Shiroma EJ, Lobelo F, et al. Effect of physical inactivity on major non-communicable diseases worldwide: an analysis of burden of disease and life expectancy. Lancet 2012;380:219-29.

19. Parkin DM. 2. Tobacco-attributable cancer burden in the UK in 2010. $B r f$ Cancer 2011;105(Suppl 2):S6-13.

20. Parkin DM. 3. Cancers attributable to consumption of alcohol in the UK in 2010. Br 7 Cancer 2011;105:S14-8.

21. Parkin DM, Boyd L. 4. Cancers attributable to dietary factors in the UK in 2010. Br 7 Cancer 2011;105(Suppl 2):S19-23.

22. Parkin DM. 5. Cancers attributable to dietary factors in the UK in 2010. $B r 7$ Cancer 2011;105(Suppl 2):S24-S26.

23. Parkin DM, Boyd L. 6. Cancers attributable to dietary factors in the UK in 2010. Br 7 Cancer 2011;105(Suppl 2):S27-30.

24. Parkin DM. 7. Cancers attributable to dietary factors in the UK in 2010. $B r F$ Cancer 2011;105(Suppl 2):S31-3.

25. Parkin DM, Boyd L. 8. Cancers attributable to overweight and obesity in the UK in 2010. Br 7 Cancer 2011;105(Suppl 2):S34-7.

26. Parkin DM. 9. Cancers attributable to inadequate physical exercise in the UK in 2010. Br 7 Cancer 2011;105(Suppl 2):S38-41.

27. Parkin DM. 10. Cancers attributable to exposure to hormones in the UK in 2010. Br 7 Cancer 2011;105(Suppl 2):S42-8.

28. Parkin DM. 11. Cancers attributable to infection in the UK in 2010. Br 7 Cancer 2011;105(Suppl 2):S49-56.

29. Parkin DM, Darby SC. 12. Cancers in 2010 attributable to ionising radiation exposure in the UK. Br 7 Cancer 2011;105(Suppl 2):S57-65.

30. Parkin DM, Mesher D, Sasieni P. 13. Cancers attributable to solar (ultraviolet) radiation exposure in the UK in 2010. Br 7 Cancer 2011;105(Suppl 2):S66-9.

31. Parkin DM. 14. Cancers attributable to occupational exposures in the UK in 2010. Br 7 Cancer 2011;105(Suppl 2):S70-2. 
32. Parkin DM. 15. Cancers attributable to reproductive factors in the UK in 2010. Br 7 Cancer 2011;105(Suppl 2):S73-6.

33. Parkin DM, Boyd L, Walker LC. 16. The fraction of cancer attributable to lifestyle and environmental factors in the UK in 2010. Br F Cancer 2011;105 (Suppl 2):S77-81.

34. Cancer risk factors in Ontario: alcohol. Toronto: Cancer Care Ontario; 2014.

35. Cancer risk factors in Ontario: healthy weights, healthy eating and active living. Toronto: Cancer Care Ontario; 2015.

36. Chen J, Tracy BL. Canadian population risk of radon induced lung cancer. Can 7 Respir Ther 2005;41:19-27.

37. Jardine K, Pahwa M, Kramer D, et al. Preventing the burden of occupational cancer in Canada: stakeholder meeting summary. Toronto: Occupational Cancer Research Centre; 2015.

Affiliations: Department of Cancer Epidemiology and Prevention Research (Grundy, Friedenreich, Poirier, Khandwala, Brenner) Alberta Health Services-Cancer Control; Department of Oncology and Department of Community Health Sciences, Cumming School of Medicine (Friedenreich, Brenner), University of Calgary, Calgary, Alta.

Contributors: Christine Friedenreich and Darren Brenner were responsible for the study conception. All of the authors contributed substantially to the study design, collected the data, drafted and revised the manuscript, approved the final version submitted for publication and agreed to act as guarantors of the work.

Funding: This project was funded by the Alberta Cancer Prevention Legacy Fund. Christine Friedenreich is supported by an Alberta Innovates - Health Solutions Health Senior Scholar Award and the Alberta Cancer Foundation Weekend to End Women's Cancers Breast Cancer Chair at the University of Calgary. Darren Brenner is supported by a Career Development Award in Prevention from the Canadian Cancer Society Research Institute.

Acknowledgements: The authors gratefully acknowledge Laura McDougall from the Alberta Cancer Prevention Legacy Fund for her support and guidance. The authors also thank Bethany Kaposhi and Lorraine Shack from the Alberta Cancer Registry for providing cancer incidence data, the department of Data Integration, Measurement and Reporting at Alberta Health Services for access to Canadian Community Health Survey data and Eileen Shaw for critical review of this manuscript.

Supplemental information: For reviewer comments and the original submission of this manuscript, please see www.cmajopen.ca/content/4/3/ E471/suppl/DC1 